\title{
El Antropoceno y el espacio común, palancas para enfrentar el cambio climático
}

\author{
The Anthropocene and the Common Space, \\ Levers to Face Climate Change \\ O Antropoceno e o espaço comum, alavancas \\ para enfrentar as mudanças climáticas
}

Sergio González-López

Recibido: 17 de enero del 2020

Aprobado: 11 de mayo del 2020

https://doi.org/10.12804/revistas.urosario.edu.co/territorios/a.8630

Para citar este artículo:

González-López, S. (2021). El Antropoceno y el espacio común, palancas para enfrentar el cambio climático. Territorios, (44), 15-32. https://doi.org/10.12804/revistas.urosario.edu.co/territorios/a.8630

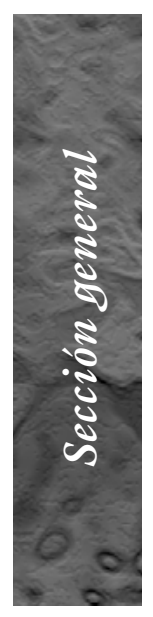

* Instituto de Estudios sobre la Universidad (IESU) de la Universidad Autónoma del Estado de México, Paseo Tollocan 1402 poniente, Cerro de Coatepec, Toluca, México. Correo electrónico: gonzalezlop.sergio@gmail. com. ORCID: http://orcid. org/0000-0003-45474210 
Palabras clave

Problemática ambiental; cambio climático; Antropoceno;

espacio común; principio precautorio; responsabilidad; riesgo.

Keywords

Environmental problematical; climate change; Anthropocene; common space; precautionary principle; responsibility; risk.

Palavras-chave

Problemas ambientais; mudanças climáticas; Antropoceno; espaço comum; princípio da precaução; responsabilidade; risco.

tersitarias 44

\section{RESUMEN}

La problemática ambiental agudizada denominada "cambio climático" ha propiciado mayores acciones para combatirla, pero han sido insuficientes y lentas ante la magnitud y urgencia requeridas. Este artículo revisa el planteamiento del Antropoceno y explora la idea del "espacio común" con el objetivo de establecerlos como palancas para impulsar enfoques más precisos que el cambio climático, porque destacan en las acciones humanas y superan la dicotomía entre lo público y lo privado, que diluye la responsabilidad en las decisiones sobre lo ambiental. Ante la prospectiva documentada del mayor riesgo de afectación drástica en las condiciones de la vida humana y, en general, del planeta, es urgente actuar con responsabilidad en la construcción de espacios que se reconozcan comunes.

\section{ABSTRACT}

The exacerbated environmental problem known as "climate change" has led to further action to combat it, but they have been insufficient and slow in the face of the magnitude and urgency required. "Anthropocene" approach is reviewed and the idea of "common space" is explored with the purpose of raising them as levers to drive more precise approaches than climate change, emphasizing human actions and overcoming the dichotomy between the public and what dilute responsibility for environmental decisions. Given the documented prospect of the increased risk of drastic negative involvement human and general life on the planet, there is an urgent need to act responsibly in construction of spaces that we recognize as common.

\section{RESUMO}

O exacerbado problema ambiental denominado "mudanças climáticas" tem propiciado maiores ações de combate, entretanto têm sido insuficientes e lentas diante da magnitude e urgência exigidas. A abordagem do "Antropoceno" é revista e a ideia de "espaço comum" é explorada com o objetivo de colocá-los como alavancas para promover abordagens mais precisas do que as mudanças climáticas, porque enfatizam as ações humanas e superam a dicotomia entre público e privado, que dilui a responsabilidade nas decisões ambientais. Dada a documentada perspectiva de maior risco de um drástico impacto nas condições da vida humana e como um todo no planeta, é urgente atuar com responsabilidade na construção de espaços que reconhecemos como comuns. 


\section{Introducción}

El futuro no es una simple prolongación lineal del presente, sino que contiene posibilidades inauditas de las cuales debemos imaginar la realización con el fin de edificar lo más temprano posible una verdadera casa común, antes de que la antigua casa se derrumbe por los efectos de la devastación despreocupada a la cual los humanos la ban sometido (Descola, 2017, p. 27).

La acción humana sobre el clima y la toma de decisiones para regularla es antiquísima, pero no hay duda de que en las últimas décadas ha tomado relevancia por la gravedad alcanzada del deterioro ambiental. Desde los setenta del siglo pasado la Organización de las Naciones Unidas (ONU) ha asumido el problema con la denominación de "cambio climático" y, converge en políticas al interior de su organismo como de otras instancias a nivel planetario, que han resultado insuficientes ante la agudeza y propagación del problema, porque aún están envueltas en la desvinculación entre la discusión científica y la toma de acciones políticas y económicas.

Entonces, es necesario reforzar conceptual y políticamente dispositivos que privilegien la responsabilidad humana y enfaticen en la urgencia de la toma de medidas. Tal es el caso del concepto de Antropoceno. Por ello, en este trabajo, en particular, se recuperan planteamientos de Bruno Latour y Philippe Descola, autores tecnocientíficos que asumen el Antropoceno y conceptos afines al de espacio común, como las "redes de zonas críticas" y los "ambientes compartidos", que contribuyen a la construcción de redes complejas de relaciones científicas, sociales y políticas para la comprensión y acción hacia problemas de alcance planetario como los señalados en el Antropoceno.

El propósito del trabajo es avanzar en la idea del "espacio común", como una palanca que amplifica el sentido de identidad y responsabilidad ante la importancia de reflexionar y actuar sobre la gravedad de la problemática ambiental, lo cual requiere del reconocimiento del planeta como el ámbito que resulta común, y a la fecha, aún no se tiene otra opción de habitación. ${ }^{1}$ La reflexión final es que, ante la prospectiva de una auténtica catástrofe ambiental en un futuro próximo, es necesario encontrar dispositivos multiplicadores o palancas que permitan reaccionar propositivamente; entre ellas, el impulso al reconocimiento del Antropoceno como una vía para dar el sentido de responsabilidad urgente en la toma de decisiones hacia el reconocimiento del planeta como espacio común.

Dicho lo anterior, este documento consta de siete apartados: los dos primeros transitan de la problemática ambiental al cambio climático; los tres siguientes tratan sobre el Antropoceno desde la tecnociencia en general, y de manera
1 Hannah Arendt ya apuntaba en su libro La condición humana (1958) que la Tierra "es la quintaesencia de la condición bumana, y la naturaleza terrena, según lo que sabemos, quizá sea única en el universo con respecto a proporcionar a los seres bumanos un hábitat en el que moverse y respirar sin esfuerzo ni artificio. El artificio humano del mundo separa la existencia humana de toda circunstancia meramente animal, pero la propia vida queda al margen de este mundo artificial y, a través de ella, el hombre se emparenta con los restantes organismos vivos" (Arendt, 1958, pp. 14-15).

territarias 44

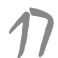


${ }^{2}$ Las Leyes de Indias fueron una compilación de leyes de indianas que se habian establecido y dado a conocer desde la segunda mitad del siglo XVI. Mi referencia a estas leyes es la señalada por Cendrero de manera textual: "Las Leyes de Indias también tuvieron en cuenta las alteraciones del medio causadas por ciertas actividades humanas. Así, la Ley VII, establece normas para el debido tratamiento de los residuos de las minas (Aspillaga Plenge, 2006): "Los defmontes, $y$ efcoriales que fe fecaren de los enfayes, y fundiciones, lamás, laves y relaves defpues de haverlos aprovechado fus dueños, con los ingenios que vfan en la forma común, fe guarden y recojan, porque eften de manifiesto para el beneficio público, vtilidad de fus dueños y aumentó de nueftra Real Hacienda (D. Felipe Tercero, en S. Lorenço, á 14 de Noviembre de 1603 )" (Cendrero, 2017, pp. 16-17).

${ }^{3}$ El Tecnógeno y el Quinario se refieren a los depósitos tecnogénicos que demuestran la acción humana sobre el planeta. Proponiéndose al Quinario como un periodo

$\Rightarrow$

territarios 44 específica recuperan ideas relevantes para los espacios comunes a la vez que se hace una aproximación al planteamiento de "dispositivo" de Foucault y Agamben $y$, se exploran algunas implicaciones del término "palanca". En las conclusiones se presentan los principales resultados, y por último, se delinea una prospectiva sobre el problema.

\section{De la problemática ambiental al cambio climático}

Las acciones humanas con la pretensión de regular su relación con la naturaleza, no son recientes. El geólogo español Antonio Cendrero (2017), señala que esta preocupación por la acción humana sobre el medio ambiente ha implicado la creación de diferentes normas desde hace más de dos mil años. Presenta varios casos, como las normas de protección ambiental implementadas por Julio César en Roma y Pompeya (siglo I a. C.), consistentes en prohibir en algunos barrios la circulación de carruajes por la producción de ruido y excrementos. También el de Eduardo I de Inglaterra, quien reglamentó en 1273 la emisión de humos. Por otra parte, las Leyes de Indias, que en 1603 establecieron normas para el debido tratamiento de residuos de minas y fundiciones, ${ }^{2} \mathrm{y}$ por último, Simón Bolívar, quien entre 1825 y 1829, promulgó decretos para la protección de la fauna, agua, conservación de bosques, salubridad del ambiente y estética de las poblaciones.
El mismo Cendrero (2017) también demuestra que los científicos desde hace décadas han resaltado la importancia de la influencia humana sobre el planeta. Menciona varios casos interesantes, como el de George Perkins Marsh — diplomático, filólogo e historiador americano-, quien publica Man and Nature. Or, Physical Geography as Modified by Human Action (1864); Antonio Stoppani - geólogo italiano-, el cual en su Corso di Geología (1871-1873), propone el término "Era Antropozoica" para referirse a ese nuevo tiempo. Así mismo, a Vladimir Vernadsky - biogeoquímico ruso- autor de La Biósfera (1926), en el cual señala que la tecnosfera es resultado de la alteración producida por el hombre. Y en 1988, George Ter-Stepanian - geólogo-, publicó su artículo Beginning of the Technogene en el cual demuestra la influencia humana en múltiples procesos atmosféricos, hidrológicos, biológicos y geológicos (internos y externos), proponiendo que el Holoceno es en realidad el 'Tecnogeno' o 'Quinario'.

En el caso de la ONU, según Jackson (2007), su interés sobre la problemática ambiental pasó de limitarse a la ocupación y uso de recursos naturales en 1949 , junto con las actividades meteorológicas realizadas a través la Organización $\mathrm{Me}$ teorológica Mundial (OMM) ${ }^{4}$ hasta 1968 , cuando incluyó las cuestiones medioambientales de manera específica al realizar la Primera Conferencia de las Naciones Unidas sobre el Medio Humano, también 
conocida como la Primera Cumbre para la Tierra, celebrada en Estocolmo (Suecia) en 1972. Desde entonces, y como lo presentan De Vengoechea (2012), Arellano (2014), Gerendas-Kiss (2018), ONU-UNFCCC (2007) y ONU-DAES (2019), se han constituido un número significativo de reuniones, documentos y órganos, entre los que se podrían señalar en una lista que no pretende ser completa: la Primera Conferencia Mundial sobre el Clima (1979); el Informe de la Comisión Mundial sobre el Medio Ambiente y el Desarrollo (1984); Desarrollo y cooperación económica internacional: Medio Ambiente. "Nuestro Futuro Común", también conocido como Informe Brundtland (1987); la creación del Grupo Intergubernamental de Expertos sobre el Cambio Climático (IPCC, por sus siglas en inglés) (1988); la conferencia marco de las Naciones Unidas sobre el cambio climático y la Primera Cumbre para la Tierra en Río de Janeiro (1992); la Primera Conferencia de las Partes sobre Cambio Climático (conocida como COPl) en Berlín (1995); la COP3 en Kioto (1997); la Agenda 2030 sobre el Desarrollo Sostenible (2015); la COP21 en París (2015); y el primer informe especial del IPCC sobre calentamiento global de $1,5{ }^{\circ} \mathrm{C}(2018)$.

La ONU es una organización compleja, en su nivel más general se puede identificar en materia climática y ambiental al Programa de las Naciones Unidas para los Asentamientos Humanos (ONU-Hábitat), el Programa de las Naciones Unidas para el Medio Ambiente (PNUMA), el Foro Político de Alto Nivel sobre Desarrollo Sostenible (FPAN), la Organización Meteorológica Mundial (OMM), el Foro de las Naciones Unidas sobre los Bosques (FNUB) y la Secretaría Interinstitucional de la Estrategia Internacional para la Reducción de los Desastres (UNISDR) (ONU, 2019).

Sin embargo, la magnitud de programas y sus esfuerzos, han distado de ser suficientes para la reducción del riesgo planetario que supone el cambio climático. Los recientes resultados del informe especial del IPCC del 2018, que había sido comprometido en la COP21 también conocida como el Acuerdo de París (2015), reveló la necesidad de limitar el calentamiento global a $1,5^{\circ} \mathrm{C}$ para evitar cambios irreversibles en la vida del planeta dando una estimación de alrededor 12 años para alcanzar este punto (Lafuente, 2019). A su vez, António Guterres, Secretario General de la ONU y los responsables de todas las agencias y divisiones, hicieron un llamado urgente a los Estados miembros de asistir a la Cumbre del Clima, a celebrarse en septiembre del 2019 en Nueva York, para que acudan con estrategias concretas y medidas realistas para limitar dicho incremento; reiteraron a los países desarrollados la obligación adquirida de alcanzar la meta de cien mil millones de dólares por año destinados para la lucha contra el cambio climático (Rusek, 2019).

sucesorio del Cuaternario, y al Tecnógeno, como época posterior al Holoceno. Véase Peloggia (1999) y Silva y Nunes (2014).

${ }^{4}$ La OMM fue establecida en marzo de 1950 y designada como un organismo especializado de la ONU desde el 17 de marzo de 1951. Su antecedente es la Organización Meteorológica Internacional (OMI) que data desde 1873 (OMM, 2019).

territorias 44 19 
${ }^{5}$ La Unesco presentó el Informe de la Comisión de Ciencias Sociales y Humanas (SHS), acordado en su Conferencia General $39^{a}$ Reunión, Paris, 2017, 11 de noviembre de 2017, que incorpora en su Anexo II la Declaración de principios éticos en relación con el cambio climático.

\section{territarias 44} 20

\section{Interpretaciones sobre el cambio climático}

El concepto de "cambio climático" fue presentado por la ONU, por vez primera en la Cumbre de Estocolmo de 1972, en específico, en su Recomendación 79 señala que de ser necesario, se establezcan nuevos programas para llegar a entender mejor la circulación general de la atmósfera y las causas de los cambios climáticos, sean esas de origen natural o resultado de las actividades humanas (ONU, 1973). Así mismo, en la Convención Marco de las Naciones Unidas sobre el Cambio Climático de 1992, la ONU define al cambio climático como "un cambio de clima atribuido directa o indirectamente a la actividad humana que altera la composición de la atmósfera mundial y que se suma a la variabilidad natural del clima observada durante períodos de tiempo comparables" (p. 3) y a los efectos adversos del cambio climático como

los cambios en el medio ambiente físico o en la biota resultantes del cambio climático que tienen efectos nocivos significativos en la composición, la capacidad de recuperación o la productividad de los ecosistemas naturales o sujetos a ordenación, o en el funcionamiento de los sistemas socioeconómicos, o en la salud y el bienestar humanos (ONU, 1992, p. 3).

La Unesco en la Declaración de Principios Éticos en relación con el Cambio
Climático, ${ }^{5}$ señala convencido la urgencia de dar respuesta al cambio climático "con políticas eficaces e integrales, que respeten y promuevan los derechos humanos y se guíen por principios éticos" (2017, párr. 7), que tienen por objetivo proclamar y establecer los "principios éticos aplicables a la adopción de decisiones, la formulación de políticas y otras actividades relacionadas con el cambio climático" (2017, párr. 20), indicando seis principios: prevención de los daños, criterio de precaución, equidad y justicia, desarrollo sostenible, solidaridad, conocimientos científicos e integridad en la adopción de decisiones. Es de resaltar que el principio ético del criterio de precaución indica que:

\begin{abstract}
Cuando haya amenaza de perjuicio grave o irreversible, no debe esgrimirse la falta de certeza científica absoluta como razón para postergar la adopción de medidas eficaces en relación con el costo destinadas a anticipar, prevenir o reducir al mínimo las causas del cambio climático y a atenuar sus efectos adversos (Unesco-sHs, 2017, pp. 30-32).
\end{abstract}

Ante la caracterización institucionalizada del cambio climático que propone la ONU, es importante presentar otros planteamientos que permitan tener una mejor comprensión de la cuestión, así como los abordajes de Antonio Arellano (2014) desde las epistemología, Manuel Arias (2011) desde las implicaciones políticas, Federico Di Pasquo et al. (2018) 
desde la perspectiva de los dispositivos, Enrique Leff (2014) quien cuestiona a la racionalidad moderna insustentable, José María Aranda y Noé Esquivel (2017) quienes proclaman una ética vital y, Hans Jonas (1979), quien plantea una ética responsable del futuro.

En ese orden, Arellano (2014) justifica abordar el cambio climático desde las epistemologías social y política, con la pretensión de superar la clásica relación hombre-naturaleza, emanada desde la Modernidad con Descartes (Arellano, 2014). A su vez, denomina "recalcitrancia epistémica modernista a la forma de producir conocimientos científicos, donde la descripción de los fenómenos mezcla causas naturales y sociales, pero separa su explicación en términos naturalísticos y sociales" (p. 13) y la aplica sobre el cambio climático. Al respecto, considera que existen "dos bandos de carácter modernista": el de las explicaciones sociológicas y el de las explicaciones naturalistas, dependiendo de a qué atribuyen las causas del cambio climático (Arellano, 2014, p. 90).

Por su parte, Manuel Arias (2011) aborda la cuestión política del cambio climático abogando por una ciencia que renuncie al sueño de la certidumbre absoluta y abra la posibilidad de adoptar cuestiones éticas en la toma de decisiones, que permitan la distinción de grados de certidumbre al momento de tomar decisiones de política pública (Arias, 2011).
Desde otra perspectiva, Di Pasquo et al. (2018) denominan como "problemática ambiental" una formación histórica que relaciona formas de saber y estructuras de poder surgidas desde finales de los sesenta en torno a lo ambiental y, para demostrar la existencia de cierta simetría "entre la forma en que el saber configuró el tema de la problemática ambiental y la forma en que el poder se estructuró para administrarlo" (p. 1), recurren al concepto de dispositivo caracterizado por Agamben (2011) a partir de Foucault. De ese modo, analizan los discursos sobre la problemática ambiental como elementos constitutivos de los dispositivos, concluyendo que sí existe una relación simétrica entre el saber científico-académico con el poder encargado de administrar la problemática ambiental, donde la forma del poder acrecentó la forma del saber y viceversa (Di Pasquo et al., 2018).

De otro lado, Enrique Leff plantea que el pensamiento humano se está alejando del sentido de la vida. En otras palabras, que la racionalidad moderna predominante piensa y actúa de una manera insustentable, que degrada y atenta contra la vida. Lo humano está ejerciendo su dominio sobre la naturaleza y conduciendo hacia muerte entrópica del planeta (Leff, 2014). Este atentado contra la vida se expresa en la crisis ambiental, a la cual el autor atribuye como una crisis civilizatoria, porque es una "crisis de los modos de comprensión, de cognición y de 
producción de conocimientos que a través de su hegemonía dominante han construido un mundo insustentable" (Leff, 2014, pp. 15-16).

Al respecto, Aranda y Esquivel plantean que los graves problemas propiciados por la fragmentación entre hombre-naturaleza representan desafíos éticos, que deben ser pensados como una ética vital que atienda todas las circunstancias que rodean la vida en su integralidad, ya que "no se trata de elaborar una ética ficticia ni de una ética del deber por el deber, sino de una ética que reconoce que ahí está su origen, su morada y que se encuentra enraizada en la Tierra, pero con proyecciones de vida nueva" (Aranda \& Esquivel, 2017, p. 9).

Probablemente, Hans Jonas es de los principales filósofos para la comprensión de la relación entre civilización contemporánea, tecnología y naturaleza, a la vez que brinda elementos fundamentales para reflexionar y actuar ética y responsablemente sobre el futuro. Su planteamiento ético tiene varios atributos que lo distinguen de otros, como no permanecer circunscrito al ámbito inmediato e impersonal de los contemporáneos. En la ampliación de la dimensión al futuro, procura no caer en la utopía idealista, otorgando al principio de responsabilidad una tarea enmarcada en el temor y el respeto. Tiene que ver con acciones más que concentradas en la especulación y sitúa a la responsabilidad en el centro de la ética de unos horizontes espacio-temporales que tienen correspondencia con los actos (Jonas, 1979).

La creciente gravedad y riesgos que se expresan en torno al clima, tienen impactos en prácticamente todos los ámbitos, demuestran la magnitud y complejidad de las implicaciones de la acción humana, así como preocupación de instituciones como la ONU y de otros múltiples actores para comprenderla y actuar en consecuencia. La problemática ambiental que se encuentra en el denominado cambio climático exige acciones más decididas y oportunas, así como su abordaje desde los múltiples ámbitos que la conforman, tal como la política y la ética, que hacen cuestionamientos sobre los efectos que está teniendo la racionalidad moderna soportada sobre bases de insustentabilidad, porque lo que está en juego es el propio futuro de la vida humana y de otras especies y, supone resaltar el papel desempeñado por uno de los principales actores: el ser humano en general, pero reconociendo la contribución desigual que han tenido en el problema grupos sociales, empresas, instituciones y gobiernos, así como la capacidad para enfrentarlo. Por lo que el abordaje desde la perspectiva del Antropoceno brinda posibilidades para enfocar la problemática desde la responsabilidad de la acción humana. 


\section{El Antropoceno desde los tecnocientíficos}

La palabra Antropoceno proviene del latín antropos $=$ hombre + koinos $=$ nuevo, es un concepto que se ha multiplicado exponencialmente en la producción científica y de divulgación, algunas divergentes sobre la fecha de su origen, alcances, sustento científico, social y político, e incluso, sobre su existencia o no. Sin embargo, pueden identificarse varios consensos predominantes, como Paul Crutzen (Premio Nobel de Química en 1995) y Eugene Stoerme, a quienes se les atribuye la paternidad del término a inicios del presente siglo. Se trata entonces de un nuevo periodo donde es significativa la influencia humana sobre el planeta, que independientemente de ser o no reconocido como era geológica, constituye una nueva manera de ver la compleja relación entre el humano con la naturaleza (Arias, 2014, 2018; Boff, 2012; Cendrero, 2017; El correo de la Unesco, 2018; Equihua et al., 2016; Franchini et al., 2017; Jones, 2011; Lanata et al., 2017; Moreno \& Conversi, 2016; Segovia, 2017; Thomas, 2017; Trischler, 2017).

En los años recientes, dos de los más destacados representantes de los estudios de ciencia, tecnología y sociedad (CTS), Philippe Descola y Bruno Latour, abrazaron la idea del Antropoceno de una manera decidida por los impactos de los humanos sobre el planeta y las implicaciones sociales, científicas y políticas de pensar y actuar en esta escala del problema. Para Descola, el Antropoceno es distinguible del proceso de antropización ${ }^{6}$ por "las implicaciones de la acción humana sobre el clima y por el efecto de este en las condiciones de vida en el planeta" (p. 18), señala la ratificación de la Comisión Internacional de Estratigrafía de la Unión Internacional de Ciencias Geológicas, de que el Antropoceno sea una época geológica auténtica, no es la cuestión central, sino las preguntas y las responsabilidades correspondientes sobre las causas y las consecuencias, y que acaso la principal dificultad o reto que implica asumir el concepto de Antropoceno, es la emergencia de la necesidad de "una nueva ciencia de las interacciones terrestres" que tendría que crearse para tomar la forma de una "amplia inteligencia colectiva" (p. 20), que combine las transformaciones medioambientales, las evoluciones de las comunidades bióticas y las prácticas humanas. Del mismo modo, plantea la necesidad de pensar en tres procesos sobre las relaciones entre los humanos y no humanos: "La manera en la cual los seres humanos se adaptan a sus entornos, la manera de apropiárselos y la manera de darles una expresión política" (Descola, 2017, p. 23).

De otra manera, Latour plantea que el concepto de Antropoceno ofrece la posibilidad de superar la tradicional oposición entre la dimensión física y la dimensión
${ }^{6}$ En contraste con el $A n$ tropoceno, es "este movimiento de coevolución de los seres humanos y no bumanos, ininterrumpido desde bace 200000 años, que moldeó el planeta, alteró los ecosistemas y sus condiciones de funcionamiento, a veces de manera irreversible y con efectos regionales no intencionales” (Descola, 2017, p. 20).

tersitarios 44

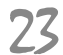


social, al establecer que es la agencia humana la principal fuerza geológica durante este periodo, lo cual también supone la necesidad de asumir la cuestión de la responsabilidad humana, dotada de historia moral, económica y política (Latour, 2014). También refiere a la posibilidad que brinda para enfrentar la urgencia y relevancia que adquiere la política en el problema, por lo que el científico no puede contentarse con desarrollar su ámbito de conocimiento sin ser empujado a la vanguardia para hacer algo al respecto, incluso, aunque no haya querido tenerlo y se contentara con la glorificación de la narración (Latour, 2014).

Así mismo, menciona que si se considera que en esta época del Antropoceno están en juego cuestiones muy grandes que afectarán a un gran número de personas, hay que hacer de lado el falso debate entre climatólogos y negacioncitas del clima, para redireccionar el problema hacia una epistemología política, pasando de una ciencia vs. política de la ciencia, a una ciencia con la política (Latour, 2013). Entonces, no existe algún conflicto entre ciencia y política — si se consigue dejar de lado que la primera trata solo sobre hechos irrefutables, y la segunda, sobre la distorsión de estos-, sino "entre dos epistemologías políticas radicalmente opuestas, cada una con su propia definición de la ciencia y la política, y qué y cómo podrían colaborar" (Latour, 2013, territarias 44 p. 7).

\section{Interpretando lo común a partir de planteamientos de tecnocientíficos}

Para contextualizar este apartado es necesario señalar que tanto Bruno Latour como Philippe Descola, por lo menos de una manera explícita, no pretenden abordar la idea de "lo común" como algo alternativo a la dicotomía entre lo público y lo privado. No obstante, estos autores ofrecen ideas relevantes en sus trabajos que tratan la cuestión del Antropoceno, los cuales se intentarán recuperar a continuación para enriquecer la idea sobre lo común. Para tal fin, en específico, se procura retomar las propuestas de "redes de zonas críticas" enunciada por Latour y "ambiente compartido" de Descola.

Ahora bien, con respecto a las redes de zonas críticas, Latour hace referencia al consorcio multidisciplinario de 22 laboratorios que lidera en París, donde las personas que ahí laboran abordan de manera colaborativa casos que estudian desde todos los ángulos posibles $\mathrm{y}$, resalta que con el trabajo colaborativo se aprende a navegar en común con datos controvertidos, compartiendo incertidumbres, modificando límites y conexiones entre la ciencia y la política, que tiene como punto de partida la consideración de que ni la política solo distorsiona los hechos, ni la ciencia solo trata hechos irrefutables e indiscutibles. Las baja de su pedestal para hacerlas más mundanas, abiertas a 
la duda y propensas al error cuando se les trata de manera desconectada (Latour, 2013, 2014).

En lo que respecta a las implicaciones de asumir el concepto de redes de zonas críticas para el abordaje del Antropoceno, el Anthropos no es un cuerpo amorfo y absoluto, sino que "se hace de redes altamente localizadas de algunos cuerpos individuales cuya responsabilidad es asombrosa" (Latour, 2014, p. 6). Dicho planteamiento supone varias precisiones sobre el ámbito del Antropoceno: si bien es global, no es uniforme, si bien nos afecta a todos, no todos somos responsables y, al encontrarse en un nivel crítico, se demanda la necesidad de tratar el problema con urgencia.

En la construcción de la visión global del Antropoceno se tejen redes históricas y locales que es necesario identificar con precisión, operando más como una especie de tapiz, que tiene nudos y huecos, donde estas relaciones entre actores sociales y científicos tiene una importancia estratégica sobre el grado de afectación reconocida y de responsabilidad asumida (Latour, 2011). Por su parte, también obliga a reconocer que no existe una desconexión entre lo científico y lo político. El propio Latour (2013), recuerda que en su trabajo Politica de la naturaleza (2004), ya demostraba que no puede trabajarse por separado entre la ciencia y la política, y proponía la definición de "política-con ciencia”, porque los políticos sin la ciencia no podrían saber las entidades que deben tomar en cuenta en sus decisiones, ni los científicos las agencias con las que tendrían que trabajar. Lo cual, supone el reconocimiento de responsabilidades compartidas.

Probablemente, el planteamiento central de Latour sobre lo común es aquel en el que señala que el mundo y situación común no es algo dado, sino algo que debe ser construido colectivamente. Se refiere a él como cosmograms, es decir, una serie de vínculos complejos entre seres humanos y no humanos, sobre los que debemos pasar de su descripción monográfica y simbólica, hacia su alcance literal de sitios críticos devastados, lo que supone, no solo "estar en la naturaleza" sino en una situación "cosmopolítica" que es común para los todos los colectivos (Latour, 2014).

Descola (2017) explícita su idea de ambientes compartidos cuando trata el proceso de apropiación, resaltando la urgencia de regresar a los bienes comunes su sentido originario, no como recurso explotable sino como ambiente que comparten las personas de manera responsable. Esto, en contraste con dos de las características fundamentales del capitalismo: que los valores indispensables de la vida pueden ser apropiados y, que estos tienen que ser considerados principalmente como recursos económicos mercantiles. Sobre este entorno común colectivamente apropiado, coincidiendo con Ostrom, señala que el acceso a estos 
bienes comunes es regido por una serie de principios considerados localmente como relevantes para ser protegidos, para el beneficio de todos, pero cuya explotación no está abierta a todos, sino como un ambiente compartido del cual cada persona que participa es responsable.

\section{De dispositivos a palancas para tratar lo común en el Antropoceno: una primera delineación exploratoria}

Para el tratamiento sobre el concepto de dispositivo, es necesario referirse en primera instancia a lo planteado por Foucault, así como a la interpretación que hace Agamben, para revisar una serie de atributos que poseen las "palancas" teniendo en mente los señalamientos previos sobre los dispositivos. Por último, se hace un ejercicio de aplicación del concepto palanca como medio capaz de potenciar la construcción de espacios comunes para enfrentar los desafíos planteados en el Antropoceno.

Giorgio Agamben resume en tres puntos el planteamiento foucaltiano sobre dispositivos:

1) [El dispositivo] se trata de un conjunto heterogéneo que incluye virtualmente cada cosa, sea discursiva o no: discursos, instituciones, edificios, leyes, medidas policíacas, proposiciones filosóficas. El dispositivo, territorias 44 26
2) El dispositivo siempre tiene una función estratégica concreta, que siempre está inscrita en una relación de poder.

3) Como tal, el dispositivo resulta del cruzamiento de relaciones de poder y de saber (Agamben, 2011, p. 250).

Agamben, para generalizar el dispositivo foucaltiano, ofrece su propia definición de dispositivo como "todo aquello que tiene, de una manera u otra, la capacidad de capturar, orientar, determinar, interceptar, modelar, controlar y asegurar los gestos, las conductas, las opiniones y los discursos de los seres vivos" (Agamben, 2011, pp. 257-258).

Compartiendo las caracterizaciones de Foucault y Agamben sobre el dispositivo, se interpreta de manera sintética como una red dinámica de relaciones potenciales realizadas entre elementos heterogéneos, que tienen una función estratégica de saberes y poderes que, generalmente responden a una urgencia. Donde, para efectos del presente trabajo interesa resaltar dos aspectos: la función estratégica de la potencialidad y realización de las relaciones, y la cuestión de la urgencia (Foucault, 1994; Agamben, 2011).

De esta manera, cuando Foucault señala "entre lo dicho y lo no dicho" refiriéndose a la heterogeneidad de elementos, y Agamben lo interpreta como "sea discursiva o no", aquí se abre la posibilidad de interpretar lo señalado por Foucault como la concreción o la 
potencialidad de concreción en el establecimiento de relaciones. Y cuando Foucault dice: "Formación que, en un momento dado, ha tenido por función mayoritaria responder a una urgencia” (1994, p. 229) y Agamben, aunque no hace señalamiento de la urgencia en sus tres puntos, sí lo indica sobre el problema de la profanación de los dispositivos. Para nosotros, la respuesta a una urgencia es resaltarla, porque esto resulta fundamental pensando en el Antropoceno al converger en la multiplicidad de elementos hacia una formación que en el corto plazo podría ser catastrófica y demanda urgentemente, detonar acciones que contribuyan a responder oportunamente al problema.

Ante la situación necesaria de respuestas urgentes y la concreción o potencialidad de realización de las relaciones en red que demanda el Antropoceno, la profundización en la reflexión sobre las implicaciones del término "palanca" puede ser estratégicamente relevante, porque otorga a los atributos ya reconocidos de los dispositivos foucaltianos, en tanto comunicantes de relaciones entre elementos diversos, la incorporación o resalte de elementos relacionales "multiplicadores" que detonen impactos magnificados, representando un salto dialéctico cualitativo ante el cambio cuantitativo.

Es del dominio público que en lo general una palanca es un objeto o máquina simple que se utiliza para amplificar la fuerza, velocidad o distancia con respecto a la fuerza inicial aplicada al contar con un punto de apoyo. También que, según la mitología griega, Arquímedes expresó en el siglo III a. C. la famosa frase: "Dadme un punto de apoyo y moveré el mundo". Por supuesto, no es interés de este texto profundizar en los atributos físicos que se otorgan a los diferentes tipos de palancas, ni tampoco si fue cierta o no dicha expresión famosa. Lo que sí interesa, es incorporar o resaltar al concepto de dispositivo algunos atributos propios de las palancas, en particular: punto de apoyo, amplificación y velocidad.

Entonces, el punto de apoyo es aquel elemento referente que hace converger dispositivos estratégicos para impulsar o contrarrestar una formación. Para efectos del Antropoceno y el espacio común, uno de los puntos de apoyo que pudiese tener esta función estratégica es el del riesgo de sobrevivencia humana y planetaria debida a la acción humana, que actualmente es tratado como una posibilidad pero no plenamente asumido como un riesgo inminente de corto plazo, que obliga a la toma de decisiones y acciones. De llegarse a tal reconocimiento y sus implicaciones, las acciones tenderían hacia su amplificación en órdenes científicos, sociales y políticos, cuestionando la separación entre ciencias y saberes comunes, el papel de los actores sociales, sus instituciones, la legitimidad y alcance de lo político en sus diferentes ámbitos. De esta manera, la relativa convergencia de visiones hacia el reconocimiento de la complejidad y urgencia para dar atención al problema, podría territarios 44 
acelerar acciones diversas para enfrentarlo; paradójicamente, una de ellas apunta de manera decidida hacia la prudencia, con base en los acuerdos necesarios para la aplicación de los principios precautorios ante los potenciales efectos negativos de la problemática ambiental que es común, porque permite superar la distinción entre las esferas públicas y privadas, que son una manera dicotómica de separación de derechos y obligaciones, es decir, de responsabilidades ante la gravedad del problema ambiental que no tiene un tiempo infinito para su enfrentamiento, sino un escenario de corto plazo por construir para poder tener alguna posibilidad de vida humana y planetaria.

\section{Conclusiones}

Como pudo observar, el cambio climático ha sido abordado con preocupación por la ONU desde principios de los setenta, y a la fecha, el secretario general de este organismo internacional continúa haciendo insistentes llamados para actuar en su combate, pues de lo contrario, en poco más de una década los daños podrían ser graves e irreversibles. Esto es indicado de la magnitud y complejidad, pero también de los insuficientes avances para resolver la problemática después de más de dos generaciones del tratamiento del problema. Ante ello, es necesario pensar opciones que posibiliten acciones más contundentes en plazos menores. En esa dirección están desde inicios de este siglo han señalado explícitamente y de manera indubitable el papel significativo de la humanidad en el proceso de deterioro y de los profundos riesgos por venir, de no modificarse esta tendencia. También pretende ubicarse la propuesta de este trabajo sobre la construcción de los "espacios comunes" a partir de los planteamientos de Latour y Descola sobre "redes de zonas críticas" y los "ambientes compartidos".

Para seguir avanzando en ese fin, de Foucault se recuperó a través de la interpretación de Agamben, el concepto de "dispositivo", teniendo en cuenta lo desarrollado en la investigación de Di Pasquo et al., que utilizan el concepto de dispositivo para tratar de manera sugerente la problemática ambiental. En este trabajo, más que pretender profundizar en el concepto y en su genealogía, se hizo la exploración de algunas de sus posibilidades analíticas a través de la incorporación de atributos del término "palanca", que se delinearon para el tratamiento del espacio común en la era del Antropoceno. La idea de la palanca es central para la selección de los dispositivos sobre los cuales se deberá mejorar la comprensión y acción para actuar ante una problemática que se está acelerando y demanda ser enfrentada con urgencia; a la vez que, permita reconocer el alcance planetario y la responsabilidad común.

Se concluye así, que ante la inminencia de una catástrofe ambiental en el corto plazo producto del quehacer humano y, 
la insuficiencia de las estrategias aplicadas a la fecha en el marco del cambio climático, es fundamental explorar dispositivos que operen como palancas para amplificar acciones de urgencia planetaria que reconozcan que la supervivencia es lo que está en juego. Para ello, la idea de 10 común, que supere la dicotomía entre los asuntos públicos y privados en la era del Antropoceno, podría contribuir para tal fin, al ser una vía para dar el sentido de responsabilidad urgente de toma de decisiones para el reconocimiento del planeta como un espacio común.

\section{Prospectiva}

Para Descola (2017), el futuro no es una mera proyección lineal del presente, sino que tiene múltiples posibilidades de realización, tanto para su destrucción - si impera la devastación despreocupada que han ejercido los humanos sobre el planeta-, como para su construcción - como una verdadera casa común-, pero esto debe ser lo más temprano posible. Entonces, de continuar tal cual el predominio de los intereses particulares de personas, organizaciones y naciones, sin asumir plenamente las responsabilidades que son comunes, muy probablemente será catastrófico social y ambientalmente en el corto plazo. Por lo cual es importante encontrar las palancas necesarias que permitan impulsar un futuro donde se reconozca que se está jugando con fuego en una probable tormenta perfecta que, para poder superarla, se debe recuperar en ese corto plazo la posibilidad de construir un futuro viable que permita vivir en común con nosotros, entre nosotros y en el entorno que nos integra con la naturaleza.

\section{Agradecimientos}

Este trabajo forma parte del proyecto de investigación "Promoción de la colaboración internacional entre posgrados sobre estudios sustentables", sin financiamiento por la UAEM. Clave 4681/2019SF.

\section{Referencias}

Agamben, G. (2011). ¿Qué es un dispositivo? Sociológica, 26(73), 294-264. http://www.scielo. org. $\mathrm{mx} / \mathrm{scielo}$.php ? pid = S018701732011000200010 \& script $=$ sci $_{-}$ arttext

Aranda, J. M., \& Esquivel, N. E. (2017). Perspectivas criticas de la ética y la ecología para el siglo XXI. UAEM; Torres $\mathrm{y}$ asociados.

Arellano, A. (2014). Cambio climático y sociedad. UAEMéx-Miguel Ángel Porrúa.

Arendt, H. (1958). La condición humana. Paidós.

Arias, M. (2011). La política del cambio climático. Revista de Libros. Segunda época, (172), 13-15. https://www. revistadelibros.com/articulo_imprimible_pdf.php?art=4913\&t=articulos

Arias, M. (2014). Antropoceno: el fin de la naturaleza. Revista de Libros. Segunda territarios 44 


\section{territarias 44}

época. https://www.revistadelibros. com/articulo_imprimible_pdf. php? $\operatorname{art}=5156 \& \mathrm{t}=$ articulos

Arias, M. (2018). Antropoceno sin Antropoceno. Eunomia. Revista en Cultura de la Legalidad, (13), 321-326. https://doi.org/10.20318/eunomia.2017.3827

Boff, L. (2012). Términos de la discusión ecológica actual. Servicios Koinonia. http://servicioskoinonia.org/boff/ articulo.php? num $=494$

Cendrero, A. (2017). El debate sobve el Antropoceno. Reflejo social, datos cientificos y aspectos formales. Discurso inaugural del año académico 2017-2018. Real Academia de Ciencias Exactas, Físicas y Naturales. http://www.rac. es/ficheros/doc/01156.pdf

De Vengoechea, A. (2012). Las cumbres de las Naciones Unidas sobre el cambio climático. Proyecto Energía y Clima de la Fundación Friedrich Ebert Sttiftung. https://library.fes.de/pdf-files/ bueros/la-energiayclima/09155.pdf

Descola, P. (2017). ¿Humano, demasiado humano?. Desacatos, (54), 16-27. http://www.scielo.org.mx/scielo. php ? script $=$ sci_arttext $\&$ pid $=$ S1607050X2017000200016

Di Pasquo, F., Busan, T., \& Klier, G. (2018). El dispositivo: problemática ambiental. CIENCIA ergo-sum, 25(1), 1-10. https://doi.org/10.30878/ces. v25nla8

El correo de la Unesco (2018, Abril-Junio). ¡Bienvenidos al Antropoceno! (n. $\left.{ }^{\circ} 2\right)$.
Unesco. https://unesdoc.unesco.org/ ark:/48223/pf0000261900_spa

Equihua, M., Hernández, A., Pérez, O., Benítez, G., e Ibañez, S. (2016). Cambio global: el Antropoceno. CIENCIA ergo-sum, Revista Cientifica Multidisciplinaria de Prospectiva, 23(1). 67-75. http://www.redalyc.org/ pdf/104/10444319008.pdf

Foucault, M. (1994). Dits et écrits 19541988. Vol. III: 1976-1979. Éditions Gallimard.

Franchini, M., Viola, E., \& BarrosPlatiau, A. F. (2017). The challenges of the anthropocene: from international environmental Politics to global governance. Ambiente \& Sociedade, 20(3), 177-202. https://doi.org/10.1590/18094422 asoc214v2022017

Gerendas-Kiss, S. (2018, 3 de noviembre). Breve historia de las COP - Conferencias sobre el Cambio Climático. SGKPLANET. https://sgerendask.com/ breve-historia-de-las-cop-conferencias-sobre-el-cambio-climatico/

Intergovernmental Panel on Climate Change (IPCC). (2018). Global warming of $1,5{ }^{\circ} \mathrm{C}$, Summary for Policymakers. IPCC. https://www.ipcc.ch/srl5/

Jackson, P. (2007). De Estocolmo a Kyoto: Breve historia del cambio climático. Crónica ONU, 44(2). https:// www.un.org/es/chronicle/article/ de-estocolmo-kyotobreve-historiadel-cambio-climatico 
Jonas, H. (1979). El principio de responsabilidad. Ensayo de una ética para la civilización tecnológica. Herder Editorial.

Jones, N. (2011). Human influence comes of age. Geologists debate epoch to mark effects of Homo sapiens. Nature, 473, 133. https://doi. org/10.1038/473133a

Lanata, J. L., Briones, C., \& Monjeau, A. (2017). La controversia sobre el Antropoceno como oportunidad: una cuestión de enfoques en lugar de designaciones formales. Interciencia, 42(3), 186-189. www. redalyc.org/service/redalyc/downloadPdf/339/33950011008/6

Latour, B. (2011). Esperando a Gaia. Componer el mundo común mediante las artes y la política. Cuadernos de Otra parte. Revista de letras y artes, 26, 67-76. http://www.bruno-latour.fr/ sites/default/files/downloads/124GAIA-SPEAP-SPANISHpdf.pdf

Latour, B. (2013, 14 y 15 de noviembre). Telling Friends from Foes at the Time of the Anthropocene (ponencia). The Anthropocene and the Global Environment Crisis - Rethinking Modernity ina New Epoch. London, Routledge. http://www.bruno-latour.fr/sites/default/files/131-FRIENDS-FOES.pdf Latour, B. (2014). Anthropology at the Time of the Anthropocene. A Personal View of What Is to Be Studied (ponencia). American Association of Anthropologists. Washington. http:// www.bruno-latour.fr/sites/default/ files/139-AAA-Washington.pdf

Leff, E. (2014). La apuesta por la vida. Imaginación sociológica e imaginarios sociales en los territorios ambientales del sur. Siglo XXI Editores.

Moreno, L., \& Conversi, D. (2016). Antropoceno, cambio climático y modelo social. Documentación Social, 183, 1330. https://tinyurl.com/ycz65qpo

Organización Meteorológica Mundial (OMM). (2019). Historia de la OMM. Organización Meteorológica Mundial. https://public.wmo.int/es/acercade-la-omm/qui\%C3\%A9nes-somos/ historia-de-la-omm

ONU. (1973). Informe de la Conferencia de las Naciones Unidas sobre el $\mathrm{Me}$ dio Humano, Estocolmo, 5-16 junio 1972. Naciones Unidas. https:// www.dipublico.org/conferencias/ mediohumano/A-CONF.48-14REV.l.pdf

ONU. (1992). Convención marco de las Naciones Unidas sobre el cambio climático. Naciones Unidas.https://unfccc.int/ resource/docs/convkp/convsp.pdf

ONU. (2019). Cronología de negociaciones sobre el clima. Naciones Unidas. https://www.un.org/sustainabledevelopment/es/cronologia-de-negociaciones-sobre-el-clima/

Rusek, A. (2019, 9 de mayo). Todos los dirigentes de la ONU piden planes urgentes contra el cambio climático. Noticias ONU. https://tinyurl.com/ybc8m79f 
Lafuente, A. (2019, 14 de marzo). Tres prioridades para salvar el planeta: consumo, biodiversidad y cambio climático. Noticias ONU. https://news.un.org/ es/story/2019/03/1452871

ONU-DAES (Departamento de Asuntos Económicos y Sociales). (2019). Principales cumbres y conferencias. Naciones Unidas. https://www.un.org/development/desa/es/about/conferences. html

ONU-UNFCCC (United Nations Framework Convention on Climate Change). (2007). 25 años de esfuerzo y logros. Hitos clave en la evolución de la politica climática internacional. https:// unfccc.int/timeline/

Peloggia, A. G. (1999). ¿ O tegnogeno existe? (conferencia). Conference: 9 Congresso Brasileiro de Geologia de Engenharia, Volume: Anais... ABGE (CD-ROM). São Paulo. https://www.researchgate.net/ publication/311495535_O_TECNOGENO_EXISTE

Segovia, A. (2017). Antropoceno: una mirada desde la historia humana y la ética ambiental. Revista Colombiana de Bioética, 12(1), 55-63. https://www.redalyc.org/pdf/1892/189251526006. pdf
Silva, É. C. N., \& Nunes, J. O. R. (2014). O tecnógeno na cidade de Presidente Prudente-SO. Sociedade \& Natureza, 26(3), 483-496. https://www.redalyc.org/pdf/3213/321332652008. pdf

Ter-Stepanian G. (1988). Beginning of the Technogene. Bulletin of the International Association of Engineering Geology, 38(1), 133-142. https:// link.springer.com/article/10.1007/ BF02590457

Thomas, J. A. (2017). Historia económica en el Antropoceno: cuatro modelos. Desacatos, (54), 28-39. http://www. scielo.org. $\mathrm{mx} /$ scielo.php? pid $=$ S1607050X2017000200028\&script $=$ sci $_{-}$ arttext

Trischler, H. (2017). El Antropoceno, ¿un concepto geológico o cultural, o ambos? Desacatos, (54), 40-57. http://www.redalyc.org/ pdf/139/13950920004.pdf

Unesco-sHs. (2017). Informe de la Comisión de Ciencias Sociales y Humanas (SHS). Conferencia General 39 a Reunión, Paris. https://unesdoc.unesco. org/ark:/48223/pf0000260101_spa 